\title{
Experimental investigation of specific cutting forces and estimation of the heat partitioning under increasing tool wear in machining nickel-based super alloy IN 718
}

\author{
Thorsten Augspurger ${ }^{1}$ [D $\cdot$ Daniel Schraknepper ${ }^{1} \cdot$ Thomas Bergs $^{1,2}$
}

Received: 28 January 2020 / Accepted: 22 June 2020 / Published online: 6 July 2020

(c) The Author(s) 2020

\begin{abstract}
Presented are an experimental setup and affiliated methodology to measure the specific cutting forces in the milling process with proceeding tool wear at simplified orthogonal milling kinematics. The cutting forces, cutter rotation angle and chip temperature are acquired by a time sensitive measuring system consisting of a synchronized dynamometer, ratio pyrometer and spindle encoder. The approach allows the accurate acquisition of cutting forces under defined engagement conditions and thus constitutes a valuable basis for cutting force modelling and tool wear monitoring approaches. The results show uniformly and linearly increasing forces over the entire range of undeformed chip thickness due to wear. Besides a mechanical view on the cutting process, also the thermal domain was included into the analysis. Therefore, a ratio pyrometer was used as part of the synchronized measurement system tracking the chips backside temperature in order to estimate a virtually continuous heat flow into the chip. This heat flow increased with wear and process power, which indicates that the chip's temperature can be used as process monitoring variable for tool wear.
\end{abstract}

Keywords Metal cutting $\cdot$ Specific cutting forces $\cdot$ Tool wear $\cdot$ Temperatures $\cdot$ Heat partitions $\cdot$ Monitoring

\section{Introduction and state of the art}

In cutting technology the force is a key indicator of the process capability in order to reach quality related as well as economic manufacturing targets. It determines the mechanical power dissipated into sensible heat causing in their interaction alternations in the workpiece microstructure as well as tool wear [1]. Finally, the force acting on the tool determines its deflection, thus machining accuracy.

The energy required and transformed in the cutting process is in particular relevant for the manufacturing of safety critical workpieces made of super alloys such as Inconel 718 or other difficult-to-cut materials. They are used in aero turbines due to their high temperature resistance, enabling

Thorsten Augspurger

t.augspurger@wzl.rwth-aachen.de

1 Laboratory for Machine Tools and Production Engineering (WZL) of RWTH Aachen University, Campus Boulevard 30, 52074 Aachen, Germany

2 Fraunhofer Institute for Production Technology, Steinbachstraße 17, 52074 Aachen, Germany an increased entrance temperature and thus efficiency of the turbine. The benefits in the application of the materials are accompanied by disadvantages in the machining process in form of high work hardening rates, abrasiveness and at the same time high toughness and low temperature diffusivity [2]. The low temperature diffusivity causes heat concentration zone in the machined surface layer which may alter the surface integrity of the component [3]. The material properties further require comparatively high cutting forces and enable only low material removal rates while shortening tool life [4]. While tool wear is considered the most relevant factor to limit the machining processes efficiency, it is likewise relevant for dimensional accuracy and a possible impairment of the surface integrity [5]. Therefore in the last years different investigations have been conducted with regard to advanced tool condition monitoring [6]. These are on the one hand black-box approaches such as [7], where form multiple sensors (such as force, acceleration, vibration, temperature, or power) features are extracted and further correlated to the tool condition by machine learning. On the other hand there are investigations working with a deterministic processing of specific signals such as force signals in order to derive specific force coefficients with proceeding tool wear. 
Mechanistic force models for cutting process combine kinematic tool engagement variables with material and process parameter specific coefficients [8]. Thus, the model is specifically adjusted to given conditions regarding tool, material and process. Common models are the exponential force model according to Kienzle [9] and the linear approach according to Altintas and Lee [10].

$F_{i, \text { Kienzle }}=k_{i} \cdot b \cdot h^{(1-m i)}$

$F_{i, \text { Altintas }}=b \cdot\left(K_{i e}+K_{i c} \cdot h\right)$.

The parameters $k_{i}$ and $m_{i}$, or $K_{i e}$ and $K_{i c}$ respectively, represent material-specific coefficients. The controversy between both models is attributed to constant ploughing term $K_{i e}$ in the Altintas model. It assumes a force when the chip thickness is $h=0$ in both, the radial and the tangential force components.

Cutting force coefficients in general depend on the tool condition with regard to the micro geometry and in particular tool wear [11]. Thus, for tool condition monitoring strategies [12] the cutting forces or cutting normal forces are often used as a valuable indicator for tool wear due to the known effect of rising force with wear propagation [13]. Therefore exploring standardized specific values for cutting forces depending on wear and effective measurement principles is of significant importance for tool condition monitoring and control strategies for different types of cutting processes [14].

In the past years several works focused on the identification of cutting force coefficients either in milling setups or analogous experiments such as orthogonal cutting. Lopez et al. [15] provided specific force coefficients depending on wear propagation and process parameters for a turning process of Inconel 718 with ceramic inserts. They present a predictive model to estimate the three force components $x, y, z$ in the straight turning process. For this purpose, the cutting force coefficients were linearized along tool wear progression depending for different cutting velocities. However, the force model does not consider the effective cross section of engagement and thus the specific force coefficients are related to the chosen tool with rhombic geometry with $\kappa_{r}=93^{\circ}$.

Similar restrictions in transferability of the measured cutting forces in $x, y, z$ direction are given in the experiments of [16] analyzing the cutting force rise due to tool wear progression in turning AISI 4340. As expected a distinctive cutting force rise with cutting time was observed increasing with feedrate. At the end of the tool's lifetime a rapid increase of radial and axial cutting forces was observed in particular for coated cutting tools, whereas a similar trend was not observed with uncoated tools. This characteristic behavior was attributed to the increase of contact area resulting from coating delamination on the nose and the flank face and the relatively lower wear rate on the rake face. The good agreement between coated tool life results obtained from normalized cutting force data and nose wear measurements demonstrated that on-line examination of the wear behavior of multi-layer ceramic coated tools can be achieved by monitoring the radial and axial force signals.

A comparative study of the cutting forces in high speed machining of Ti-6Al-4V and Inconel 718 for varying cutting speeds and feed rates was conducted in [17]. Therefore orthogonal cuts in a planning setup provided the cutting and thrust force, which were both normalized by the width of cut offering comparability. However, the influence of tool wear was not investigated.

For fiber reinforced plastics Schulze et al. [8] determined specific cutting, passive and axial forces for varying cutting velocity, cutting depth, cutting edge rounding and tool inclination in orthogonal cutting. The overall objective of the resulting regression models was to implement them in a kinematic simulation tool, which then allows calculating machining forces and their direction for arbitrary milling operations.

Besides the analogous experiments, such as orthogonal cutting, several works focused on the identification of cutting force coefficients in the process by fitting modelled and measured force waveforms online or offline. Recently Schwenzer et al. [11] conducted a comparative study on optimization algorithms for online identification of an instantaneous Kienzle force model in milling. They aimed for decreasing the experimental effort to calibrate mechanistic force models and at the same time provided an online calibration to consider uncertainties inherently (such as the tool wear state or material characteristics) for an accurate force control in milling. A variety of derivativefree optimization algorithms in order to solve the nonlinear curve-fitting problem was used [18]. However, only constrained optimization algorithm seemed to reliably provide a solution that is in accordance with the existing literature.

Most other works identified the coefficients for the linear Altintas model or a linear derivative either by the method of average forces or instantaneous uncut chip thickness. One way is to average the force signal over a multiple engagements and feed variations deriving a functional relationship through regression. However, this requires a high experimental effort. Grossi [19] suggested a ramp-up method in order to acquire speed-varying coefficients with a single test. An extended approach to determine coefficients by averaging was suggested by Auerbach et al. [20] by automatically conducting the experiments. The technology assistance system standardized and automated executes the test and generates models to describe the machinability criteria for a given parameter range, serving as input for 
a future optimization. Examples for the calibration of a force model by the instantaneous cutting force are given for instance by Wan et al. [21] and Wang et al. [22].

With regard to the mentioned potentials on force based tool wear monitoring and the huge advances in online parameter identification a methodology is desirable in order to effectively determine wear-dependent force coefficients under known engagement conditions. The state-of-the-art method is the orthogonal cutting test providing definite engagement conditions [17]. However, it lacks from effectiveness since multiple cuts are required in order to obtain a representative tool wear state [8]. An online identification of the coefficient has the drawback of undefined engagement conditions with regard to tool deflection, dynamics and run out error. Finally, often an ill posed optimization problem is solved providing only a potential solution. If the reliable cutting force coefficients over tool wear would be known this solution could suffice for process monitoring with regard to dynamics, run out, deflection, and wear.

This publication presents a simple and effective approach in order to determine cutting force coefficients depending on tool wear for the milling process. Therefore, an experimental orthogonal milling setup was used integrating a synchronized sensor system with dynamometer, ratio pyrometer and spindle encoder as already introduced in the authors previous work [3]. This setup not only enables the analysis of forces but also the monitoring of transient temperature fields and heat partitions in the workpiece, the tool and the chip.

\section{Experiments and post processing of cutting forces}

For the orthogonal down-milling experiment shown in Fig. 1 of Inconel 718 a single-tooth, tailor-made, uncoated end milling cutter was used (diameter $d=20 \mathrm{~mm}$, rake angle $\gamma_{n}=6^{\circ}$, clearance angle $\alpha_{n}=12^{\circ}$, cutting-edge rounding $r_{\beta}<5 \mu \mathrm{m}$, no helix angle, width of cut $w=3.4 \mathrm{~mm}$ ). The tool consisted of a $10 \%$ cobalt-tungsten carbide. The parameter setting radial depth of cut $a_{e}=3.75 \mathrm{~mm}$, axial depth of cut equals the workpiece thickness $a_{p}=3 \mathrm{~mm}$, and the feed per tooth $f_{z}=0.05 \mathrm{~mm}$ was constant. Those parameters resulted in an effective cutting length of $8.95 \mathrm{~mm}$ during a cutting time of $0.076 \mathrm{~s}$ per stroke. Those are the same specifications for both the workpiece as well as for the tool material as were used in the former published experiments [3].

A run-out error could be excluded due to the one tooth cutter as well as possible tool deflection due to the large diameter $d=20 \mathrm{~mm}$ in relation to the unclamped tool length of approximately $l_{\text {clamp }}=40 \mathrm{~mm}$. Furthermore, a circumferential down-milling process with no helix angle was performed simplifying the relation between feed per tooth, undeformed chip thickness and cutter rotation angle to:
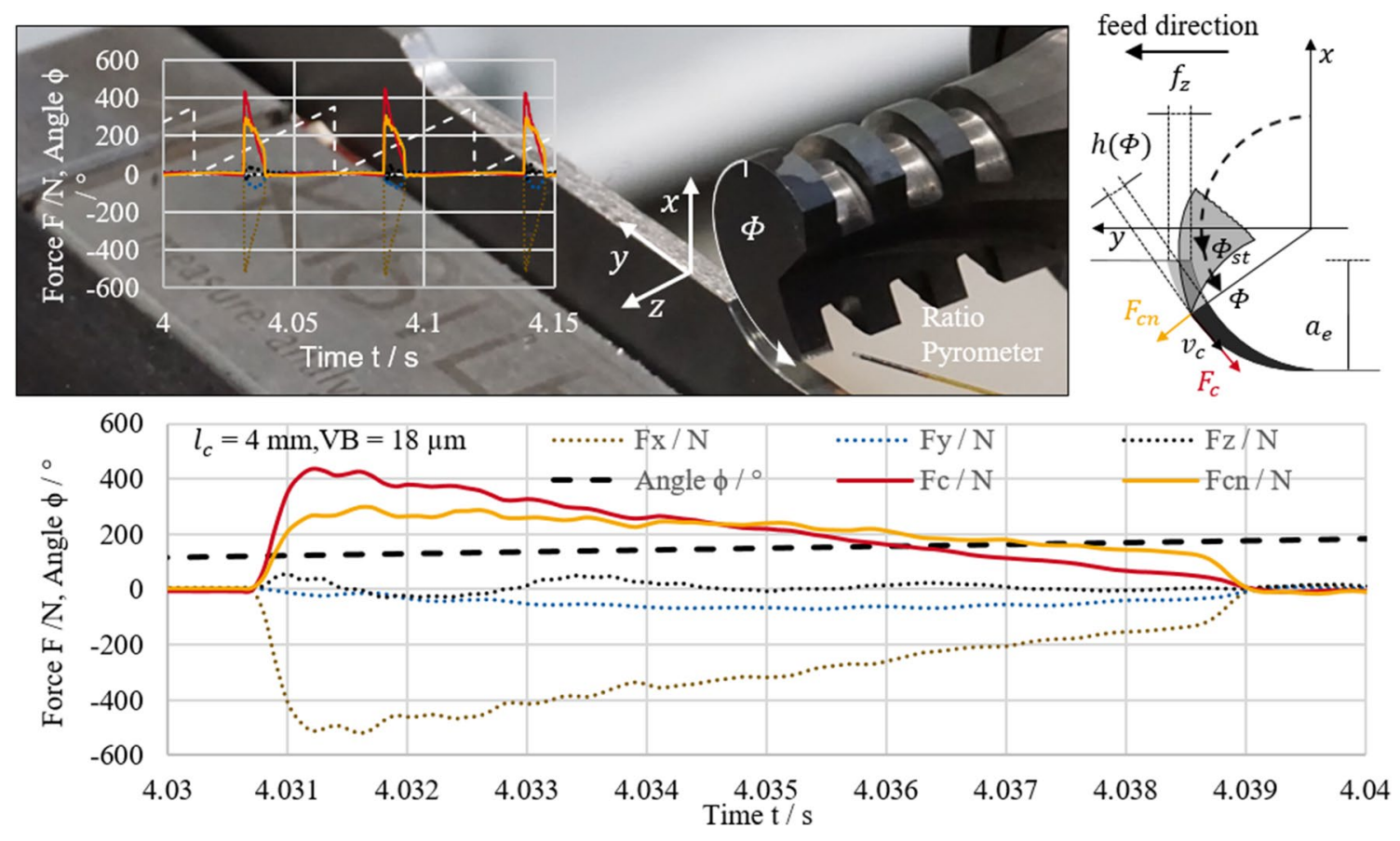

Fig. 1 Cutting force components at $\mathrm{v}_{\mathrm{c}}=70 \mathrm{~m} / \mathrm{min}, \mathrm{a}_{\mathrm{e}}=3,75 \mathrm{~mm}, \mathrm{a}_{\mathrm{p}}=3 \mathrm{~mm}, \mathrm{l}_{\mathrm{c}}=14 \mathrm{~mm}$ 
$h_{\Phi}=f_{z} \cdot \sin (\Phi)$.

For the experiment a sensor system was constituted for the measurement of temperatures and forces enabling the subsequent calculation of heat flows and the mechanical power of the milling process. This measurement system as well as the experimental kinematics was previously introduced in [3] in order to measure heat partitions between workpiece, and chip as well as validate transient, volumetric temperature fields in the milling process in the tool and the workpiece.

A field programmable gate array (FPGA) within a NI COMPACTRio 9148 was used in order to initialize the various measuring systems and to process the incoming signals time-deterministically, both from the machine and the sensors at a sample rate of $10 \mathrm{kHz}$.

The ratio pyrometer of type Fire 3, manufactured by en2Aix, measured the absolute temperature at the backside of the chip and, together with kinematic considerations, allowed an estimation of the maximum possible internal energy carried away by each chip over time. This way a theoretical, per definition continuous heat flow with a temporal resolution $t$ of one rotation $1 / n$ was estimated. The ratio pyrometer worked with an internal cut off frequency of $45 \mathrm{kHz}$ sampled at $10 \mathrm{kHz}$ by the FPGA.

A dynamometer measured the components of the active force $F_{a}$ in the working plane $P_{f}$. The multicomponent dynamometer type Kistler 9129AA was used and controlled via a 4 channel charge amplifier of type KISTLER 5070 , sampled at $10 \mathrm{kHz}$ by the FPGA.

A spindle encoder provided the actual cutter rotation angle $\Phi$. For this purpose, the spindle encoder's signal was processed by the FPGA. The encoder sampled two mutually phase-shifted code tracks which are scanned with a light-emitting diode. The sensor provided two square-wave signals determining both the position of the spindle and the direction of rotation over 1024 segments per revolution and thus a resolution of $0.3^{\circ}$. The cutter rotation angle was set to zero at the 12 o'clock position using a dial gauge.

A transformation in peripheral coordinates was obtained by:

$\left[\begin{array}{c}F_{c} \\ F_{c n} \\ F_{p}\end{array}\right]=\left[\begin{array}{ccc}-\sin \Phi+\cos \Phi & 0 \\ \cos \Phi & +\sin \Phi & 0 \\ 0 & 0 & 1\end{array}\right] \cdot\left[\begin{array}{l}F_{x} \\ F_{y} \\ F_{z}\end{array}\right]$.

The mean mechanical process power, which dissipated largely into sensible heat, was calculated by:

$P=F_{c, \text { mean }} \cdot v_{c}$.

Under these conditions and a cutting velocity of $v_{c}=70 \mathrm{~m} / \mathrm{min}$ the tool was progressively exposed to wear over intervals until a path length of $l_{\text {cut }}=144 \mathrm{~mm}$ and 2880 rotations for the single tooth was reached. Tool wear was measured frequently in form of max flank wear $V B$ on the flank face as indicated in Fig. 2 at the top.

Figure 1 shows the kinematics of the orthogonal milling process and a selected example of the resulting cutting force measurements including the transformed force components.

The force signals over a duration of one second were used for the evaluation. The cutting forces were assigned to the corresponding undeformed chip thickness defined by Eq. (3) at the corresponding cutter rotation angle. However, before each run the cutter rotation angle was set manually to zero with an accuracy of approximately three degrees. This variance became obvious in the data post processing in form of slight temporal offsets between the trends. It was compensated manually by adjusting the cutter rotation entry angle $\Phi_{s t}$. However, despite small remaining displacements the cutting forces show a distinctive waveform pattern over the undeformed chip thickness as shown in Fig. 2. Increasing wear shifts the curves to higher cutting forces over the entire range of undeformed chip thickness without altering their form until a tool wear of $213 \mu \mathrm{m}$. However, at this state the tool has lost its definite geometry and with it the comparability to the former states.

Tool wear at a low level $V B<100 \mu \mathrm{m}$ seems to increase the forces uniformly and linearly. The rise due to wear is small, however distinctive, with little variance.

At the highest measured tool wear $V B=213 \mu \mathrm{m}$ the cutting normal force shows the highest relative increase and remains at almost the same level above an undeformed chip thickness $\mathrm{h}=0.005 \mathrm{~mm}$.

The dependency between force and undeformed chip thickness also seems to be linear in the investigated case. This becomes especially evident considering the normalized cutting forces as shown in Fig. 2 middle section. Above $h=0.01 \mathrm{~mm}$ there seems to be no dependency between normalized cutting force $F_{c}$ and undeformed chip thickness $h$ at all. Only the influence of the tool wear is present. This confirms the former statements of the cutting force to be a reliable value in order to evaluate the tool wear state also in process monitoring applications.

The introduced methodology and experimental setup offers several opportunities for a process and tool micro geometry qualification with regard to an overall machinability. A huge advantage compared to orthogonal cutting test is the possibility to execute multiple engagements and thus proceeding tool wear. The milling kinematics further cover areas of the undeformed chip thickness close to zero, which typically form the surface and have relevance with regard to process induced alterations of the surface's metallic microstructure. Those 


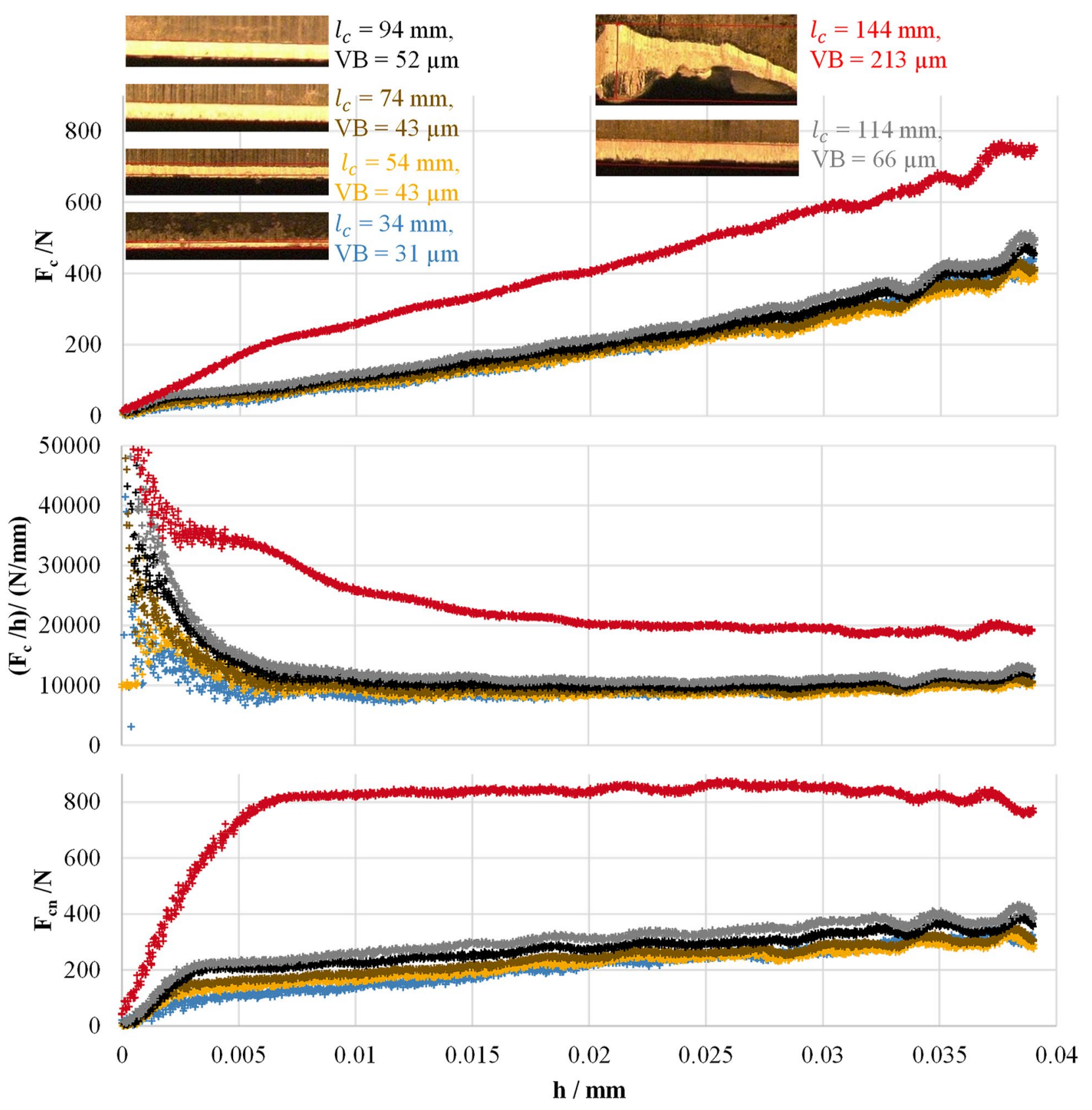

Fig. 2 Cutting force and cutting normal force depending on undeformed chip thickness $\mathrm{h}$ and tool wear land

areas of low undeformed chip thickness demand a wear resistant tool design with regard to microgeometry, cutting edge rounding and coating.

\section{Post processing of pyrometer measurements}

Besides the mechanics of the cutting process and proceeding tool wear, the thermal domain was considered. Therefore, a ratio pyrometer was used as part of the synchronized measurement system. This pyrometer measured the chip temperature from a stationary position related to the rotating cutter as shown in Fig. 1. At the cutter rotation exit angle $\phi_{e x}$ the focus of the fiber solely fixed the chips' backside. Its diameter was less than $1 \mathrm{~mm}$ at this position, which was measured by sending a light emitted by a laser in the opposite direction through the fiber.

Figure 3 in the top diagram shows the measured cutting force and the corresponding temperature of the chip for two different tool path lengths $l_{c}=34$ and $144 \mathrm{~mm}$, respectively. The signals were compared at approximately $19.5 \mathrm{~s}$ after 


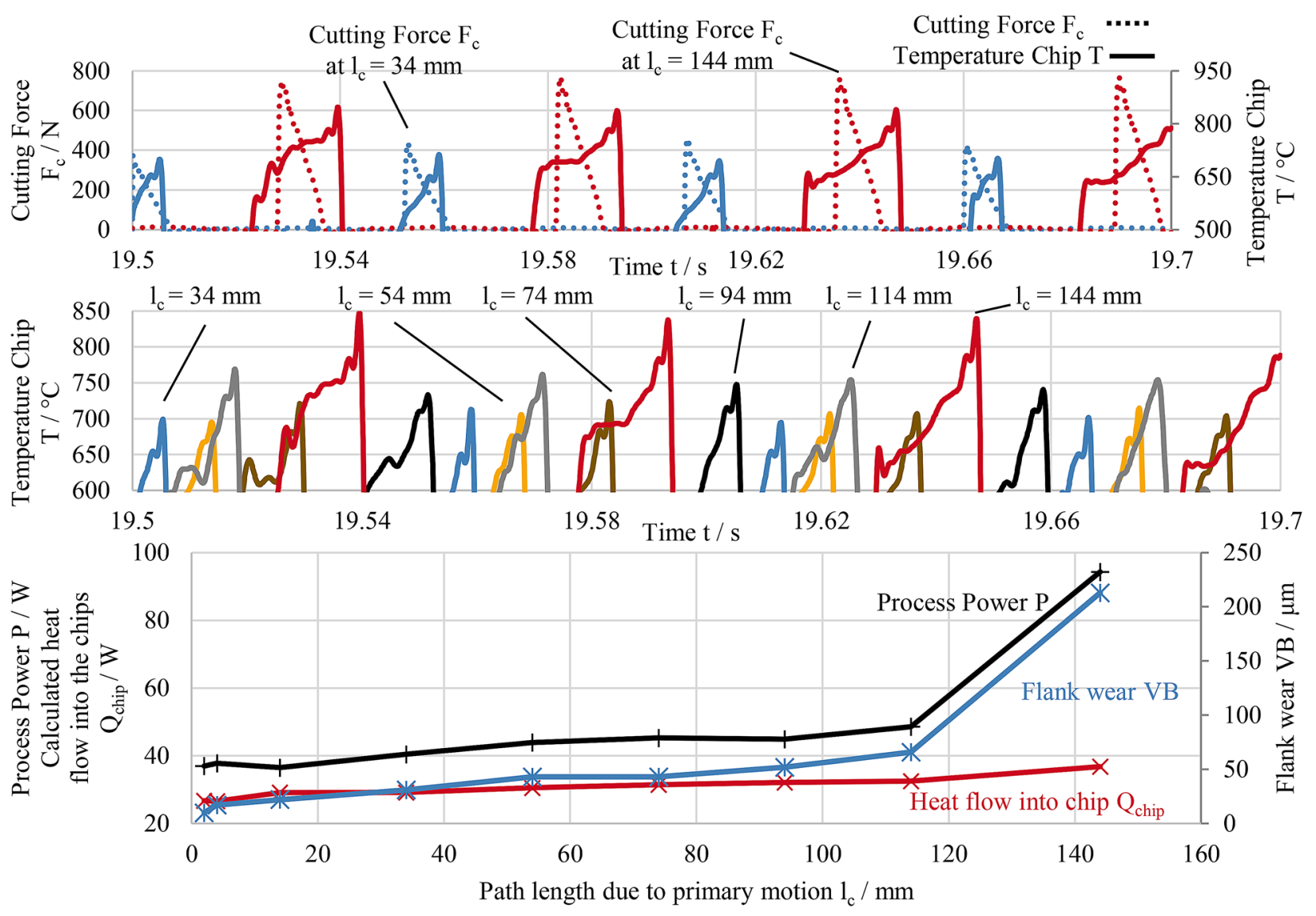

Fig. 3 Rise of process power and heat carried away by the chips with increasing tool wear

the beginning of cutting, when the process reached a steady state. It was observed, that the chip temperature rises until this duration, which probably was due to a settling steady state, in particular with regard to the tool temperature as well as the temperature field in the workpiece as demonstrated in [3]. The diagram shows the rising cutting force due to tool wear and the respective rise of the chip temperature. This rise is visible along the entire tool wear progress, Fig. 3 middle. However, the effect is more distinctive with increasing path length and thus tool wear. It may be explained with the rising cutting force due to proceeding wear and its dissipation into the sensible heat, which is mainly carried away in form of the chips' internal energy.

For the cutting length $l_{c}=144 \mathrm{~mm}$ a temperature signal rise before the cutting force rise, thus tool engagement, is visible in Fig. 3, in top graph. This may be explained by the reflection of the still hot chip of the former engagement sticking to the cutting edge and now reflecting on the workpiece surface, which is visible for the ratio pyrometer fiber due to its orientation. The orientation could not be varied significantly in the experimental setup. This shows the timing to be a crucial aspect of the measured temperature signal interpretation.
In order to be sure to measure the chip itself, the maximum temperature $T_{\text {chip,max }}$ per revolution, occurring at a cutter engagement angle of $\Phi_{e x}=180^{\circ}$, was considered, where the chip has its minimum thickness. However since the chip reaches its minimum thickness at this point it probably has a virtually homogenous temperature profile. This is not the case at higher chip thicknesses due to the restricted tool face heat source penetration capability into the chip orthogonal to the mass flow as observed in former investigations [23].

As a result of this effect and by assuming a homogenous $T_{\text {chip,max }}$ in the entire chip volume $V_{\text {chip }}$ the total internal energy in the chip is overestimated

$V_{\text {Chip }}=a_{p} \int_{\Phi_{e x}}^{\Phi_{s t}} \frac{d}{2} \cdot f_{z} \cdot \sin \Phi \cdot d \Phi$.

Furthermore, only the overall maximum temperature of the chip backside $T_{\text {chip,max }}$ measured during one test run with several engagements was considered together with a heat capacity $c_{p}\left(T_{\text {chip,max }}\right)$, described in [3], depending on 
this temperature, in order to estimate a maximum virtually continuous heat flow into the chips:

$\dot{Q}_{\text {chip, max }}=U_{\text {chip }} \cdot n=V_{\text {Chip }} \cdot \rho \cdot c_{p}\left(T_{\text {chip, } \max }\right) \cdot\left(T_{\text {chip, } \max }-20^{\circ} \mathrm{C}\right) \cdot n$.

This simplification ignores sticking chips of the former cuts, which frequently cover the recently cut chip, distorting the measurement. However, under this simplification the temporal resolution is lost, at least restricted. Under ideal conditions the method provides a continuous monitoring of the cutting process and maximum estimation of the heat transported away by the chips. The unsteady heat flow into the chip was further assumed as virtually continuous during the process. In reality, it occurs in portions constituted by each chip.

Figure 3 at the bottom shows the increase of flank wear, process power and calculated heat flow into the chips with proceeding path length $l_{c}$ due to primary motion. Obviously, not only the cutting force and thus process power follows the rise of tool wear, but as well the temperature of the chip backside and therefore the estimated maximum heat flow into the chip. The heat partition into the chip reaches around $70 \%$ of the total process power, which is in accordance with the order calculated in [3].

From a physical perspective both, the absolute rise of heat flow into the chip as well as the constant partitioning are plausible, since the increasing process power with wear is dissipated into sensible heat, which is either conducted into the tool, workpiece or the chips. This partition mainly depends on the process parameters in relation to thermal material properties [3]. It should be noted that the process power increases from $48 \mathrm{~W}$ at $l_{c}=114 \mathrm{~mm}$ to $94 \mathrm{~W}$ at $l_{c}=144 \mathrm{~mm}$, whereas the estimated heat flow into the chips only increases from 32 to $37 \mathrm{~W}$. This indicates an increasing heat partition into the tool and probably in particular into the workpiece, since the principal heat partitioning takes place between chips and workpiece. These results indicate the usefulness of the ratio pyrometer as an indirect measurement system for tool wear in machining under dry conditions, but also with regard to wear related increase in heat flows and temperatures with regard to surface integrity considerations.

\section{Conclusions}

The publication introduced an experimental setup in order to accurately and efficiently derive specific cutting forces under proceeding tool wear. This approach combines simplified milling kinematics with a synchronized measurement system of a dynamometer, pyrometer and a spindle encoder. From a scientific perspective, it offers a standardized approach to derive comparable specific cutting forces for materials, tool geometry, coating systems and process parameters. The mechanistic view further may be included in a comprehensive thermo-mechanical approach focusing the entire heat partition in the cutting zone, on transient temperature variations in the tool as well as the moving temperature field in the workpiece as introduced in [3].

Initial considerations with regard to the measured process power as well as heat flow into the chips show the effect of tool wear on the rising mechanical process power and the virtually continuous heat flow into the chip estimated from the chips' backside temperature. This temperature was measured by a ratio pyrometer possibly sufficing as an indirect tool wear and surface integrity monitoring system.

Acknowledgements Open Access funding provided by Projekt DEAL. The authors wish to thank the German Research Foundation (DFG) for funding the transregional Collaborative Research Center SFB/TR 96 "Thermo-Energetische Gestaltung von Werkzeugmaschinen" subproject A02.

Open Access This article is licensed under a Creative Commons Attribution 4.0 International License, which permits use, sharing, adaptation, distribution and reproduction in any medium or format, as long as you give appropriate credit to the original author(s) and the source, provide a link to the Creative Commons licence, and indicate if changes were made. The images or other third party material in this article are included in the article's Creative Commons licence, unless indicated otherwise in a credit line to the material. If material is not included in the article's Creative Commons licence and your intended use is not permitted by statutory regulation or exceeds the permitted use, you will need to obtain permission directly from the copyright holder. To view a copy of this licence, visit http://creativecommons .org/licenses/by/4.0/.

\section{References}

1. Brinksmeier E, Klocke F, Lucca A, Sölter J, Meyer D (2014) Process signatures-a new approach to solve the inverse surface integrity problem in machining processes. Procedia CIRP 13:429-434

2. Choudhury IA, El-Baradie MA (1998) Machinability of nickelbase super alloys: a general review. J Mater Process Technol 77(1-3):278-284

3. Augspurger T, Bergs T, Döbbeler B (2019) Measurement and modeling of heat partitions and temperature fields in the workpiece for cutting Inconel 718, AISI 1045, Ti6Al4V, and AlMgSi0.5. J Manuf Sci Eng 141(6):61007

4. Dudzinski D, Devillez A, Moufki A, Larrouquère D, Zerrouki V, Vigneau J (2004) A review of developments towards dry and high speed machining of Inconel 718 alloy. Int J Mach Tools Manuf 44(4):439-456

5. Ezugwu EO (2005) Key improvements in the machining of difficult-to-cut aerospace superalloys. Int J Mach Tools Manuf 45(12-13):1353-1367

6. Teti R, Jemielniak K, O’Donnell G, Dornfeld D (2010) Advanced monitoring of machining operations. CIRP Ann Manuf Technol 59/2, ISSN 0007-8506(CIRP Annals):717-739

7. Segreto T, Simeone A, Teti R (2012) Sensor fusion for tool state classification in Nickel Superalloy high performance cutting. Procedia CIRP 1:593-598 
8. Schulze V, Becke C, Pabst R (2011) Specific machining forces and resultant force vectors for machining of reinforced plastics. CIRP Ann 60(1):69-72

9. Kienzle O, Victor H (1952) Die Bestimmung von Kräften und Leistungen an spanenden Werkzeugen und Werkzeugmaschinen. In: VDI-Z 94, 11/12, pp 299-305

10. Altintas Y, Lee P (1996) A general mechanics and dynamics model for helical end mills. CIRP Ann 45(1):59-64

11. Schwenzer M, Auerbach T, Döbbeler B, Bergs T (2019) Comparative study on optimization algorithms for online identification of an instantaneous force model in milling. Int J Adv Manuf Technol 101(9-12):2249-2257

12. Byrne G, Dornfeld D, Inasaki I, Ketteler G, König W, Teti R (1995) Tool condition monitoring (TCM) — the status of research and industrial application. CIRP Ann 44(2):541-567

13. Prickett PW, John C (1999) An overview of approaches to end milling tool monitoring. Int J Mach Tools Manuf 39(1):105-122

14. Lin SC, Ting CJ (1995) Tool wear monitoring in drilling using force signals. Wear 180(1-2):53-60

15. López de Lacalle LN, Urbicain Pelayo G, Fernández-Valdivielso A, Alvarez A, González H (2017) Wear-dependent specific coefficients in a mechanistic model for turning of nickel-based superalloy with ceramic tools. Open Eng 7(1):581

16. Cho S-S, Komvopoulos K (1998) Cutting force variation due to wear of multi-layer ceramic coated tools. J Tribol 120(1):75

17. Fang N, Wu Q (2009) A comparative study of the cutting forces in high speed machining of Ti-6Al-4V and Inconel 718 with a round cutting edge tool. J Mater Process Technol 209(9):4385-4389

18. Schwenzer M, Stemmler S, Ay M, Bergs T, Abel D (2019) Ensemble Kalman filtering for force model identification in milling. Procedia CIRP 82:296-301
19. Grossi N (2017) Accurate and fast measurement of specific cutting force coefficients changing with spindle speed. Int J Precis Eng Manuf 18(8):1173-1180

20. Auerbach T, Gierlings S, Veselovac D, Seidner R, Kamps S, Klocke F (2015) Concept for a technology assistance system to analyze and evaluate materials and tools for milling. In: Proceedings of the ASME Turbo Expo 2015. Turbine technical conference and exposition, June 15-19, 2015, Montreal, Quebec, Canada. ASME Turbo Expo 2015: Turbine Technical Conference and Exposition, Montreal, Quebec, Canada. Monday 15 June 2015. ASME, New York, N.Y., V006T21A006

21. Wan M, Zhang WH, Tan G, Qin GH (2016) New algorithm for calibration of instantaneous cutting-force coefficients and radial run-out parameters in flat end milling. Proc Inst Mech Eng Part B J Eng Manuf 221(6):1007-1019

22. Wang G, Peng D, Qin X, Cui Y (2012) An improved dynamic milling force coefficients identification method considering edge force. J Mech Sci Technol 26(5):1585-1590

23. Augspurger T, Bergs T, Döbbeler B, Lima A (2019) Methodology for the measurement of the heat partitioning by thermal imaging in the orthogonal cutting process. ASME J Heat Transf 141(7):072101. https://doi.org/10.1115/1.4043170

Publisher's Note Springer Nature remains neutral with regard to jurisdictional claims in published maps and institutional affiliations. 